\title{
PREVENÇÃO DE ACIDENTES NO AMBIENTE DOMÉSTICO: DISCUTINDO O COMPORTAMENTO PREVENTIVO NA FAMÍLIA
}

\author{
PREVENTION OF ACCIDENTS IN THE DOMESTIC ENVIROMENT: \\ DISCUSSING THE PREVENTIVE BEHAVIOR IN THE FAMILY \\ PREVENCIÓN DE ACCIDENTES EN LAAMBIENTE DOMÉSTICO: \\ DISCUTIENDO EL COMPORTAMENTO PREVENTIVO EN LA FAMILIA
}

Éllen Cristina Santana Aleixo* Magda Lúcia Félix de Oliveira**

\begin{abstract}
RESUMO: O comportamento preventivo familiar é resultado da interação da família com profissionais de saúde, com a mídia e com pessoa de seu ambiente. Realizou-se levantamento bibliográfico sobre o tema prevenção de acidentes no ambiente familiar, com o objetivo de discutir medidas facilitadoras de comportamento preventivo de intoxicações infantis. Destacam-se as intervenções ativas e passivas como medidas de prevenção de acidentes, sendo que as medidas passivas de prevenção são mais eficazes, por não dependerem da intervenção do indivíduo mas de toda a sociedade. No entanto, reforça-se a necessidade de mudança na formação dos profissionais que trabalham na saúde bem como de uma nova postura dos formuladores das políticas públicas, através do controle dos novos produtos lançados no mercado nacional.
\end{abstract}

PALAVRAS CHAVE: Acidentes domésticos; Prevenção de acidentes; F amília

\section{INTRODUÇÃO}

0 assunto abordado neste estudo é resultado de um levantamento bibliográfico sobre o tema, visto que atuamos em um Serviço no qual a prevenção de intoxicações e a educação para a saúde se destaca entre as nossas atividades.

É uma postura reflexiva sobre a prevenção de acidentes infantis no ambiente familiar, pois acredita-se que tais acidentes podem ser evitados se toda a sociedade se engajar na busca de meios que possam contribuir para a diminuição do risco.

Considera-se infância a fase na qual o comportamento preventivo deve ser mais enfatizado, pois esta etapa da vida, dependendo das experiências vivenciadas pode deixar marcas significantes no desenvolvimento do ser humano.

A infância é feita de uma sucessão de etapas de desenvolvimento, cada uma com suas particularidades, de forma contínua, através de um processo global. Neste processo existe um ritmo próprio de cada criança, tanto no desenvolvimento motor quanto no intelectual, social e afetivo (Whaley; Wong, 1989).

Este período da vida é tão importante que a sociedade e os governos do mundo todo têm criado leis para protegê-lo. A criança precisa de proteção, carinho, tempo livre para brincar, além de todas as oportunidades para crescer sadia e estudar (Brasil,1998).

* Enfermeira do Hospital Universitário Regional de Maringá. Mestre em Saúde Coletiva. Email: sec-cci@ uem.br

** Enfermeira.Docente do Departamento de Enfermagem da Universidade Estadual de Maringá. Coordenadora do Centro de Controle de Intoxicações do Hospital Universitário de Maringá. Mestre em Saúde Coletiva. 


\section{ACIDENTES DOMÉSTICOS: FATORES DE RISCO, CONSEQUÊNCIAS E FORMAS DE INTERVENÇÃO}

Para a Organização Mundial de Saúde (OMS), "acidente é um acontecimento independente da vontade humana, desencadeado pela ação repentina e rápida de uma causa externa, produtora ou não de lesão corporal e/ou mental" (Back, et al., 1989, p.379-391).

Durante a infância as crianças são susceptíveis a acidentes, que podem ocorrer em qualquer lugar e variam segundo o tipo, a gravidade e a extensão do dano ocasionado. Os acidentes na infância acontecem independentemente da classe sócioeconômica, idade, sexo, cor das crianças e de suas famílias (Santos,1988).

Dados da OMS, citados em Del Ciampo; Ricco (1996), apontam que $45 \%$ dos acidentes com a população mundial ocorre no lar, $30 \%$ nos locais públicos, $14 \%$ nos locais de trabalho e $10 \%$ nas auto-estradas.

Para Back et al. (1989), os acidentes têm relação com vários fatores comuns: sociais, ecológicos, culturais, relacionados à civilização, à condição física ou psicológica e ao crescimento e desenvolvimento, principalmente das crianças. Esses autores enfatizam que não existe ambiente sem risco, o que existe é um maior perigo em determinados locais.

Enfocando especificamente os acidentes na infância, Santos (1988), destaca que as circunstâncias dos acidentes geralmente são criadas pela própria criança. No entanto, estes podem ser evitados, em mais de $75 \%$ das ocasiões, por um adulto.

Del Ciampo e Ricco (1996), ressaltam que as crianças possuem características próprias que as tornam mais propensas à acidentes e destacam entre elas:

"sua imaturidade física e mental, a inexperiência e incapacidade para prever e evitar situações de perigo, grande curiosidade, motivação em realizar tarefas, tendências a imitar e repetir comportamentos, falta de preocupação corporal, ignorância, impaciência, incoordenação motora, além de particularidades orgânicas ou anatômicas como a desproporção crânio-corpo e as pequenas dimensões das vias aéreas superiores que podem predispor a acidentes mais específicos. Além disso, as crianças muitas vezes vivem em meios sociais desfavoráveis, principalmente em níveis sócioeconômicos inferiores, devido a superpopulação, miséria, educação e vigilância insuficientes, necessitando adaptar-se ao mundo dos adultos, que lhes é hostil e desconhecido, tendo que freqüentemente adquirir conhecimento pelo método de tentativa e erro".

0 quadro 1 destaca os tipos de acidentes mais freqüentes nas faixas etárias específica, e foi adaptado de Schilling, et al. (1994).

QUADRO ..O.D.AD.A.RQ..ADA AA RA...

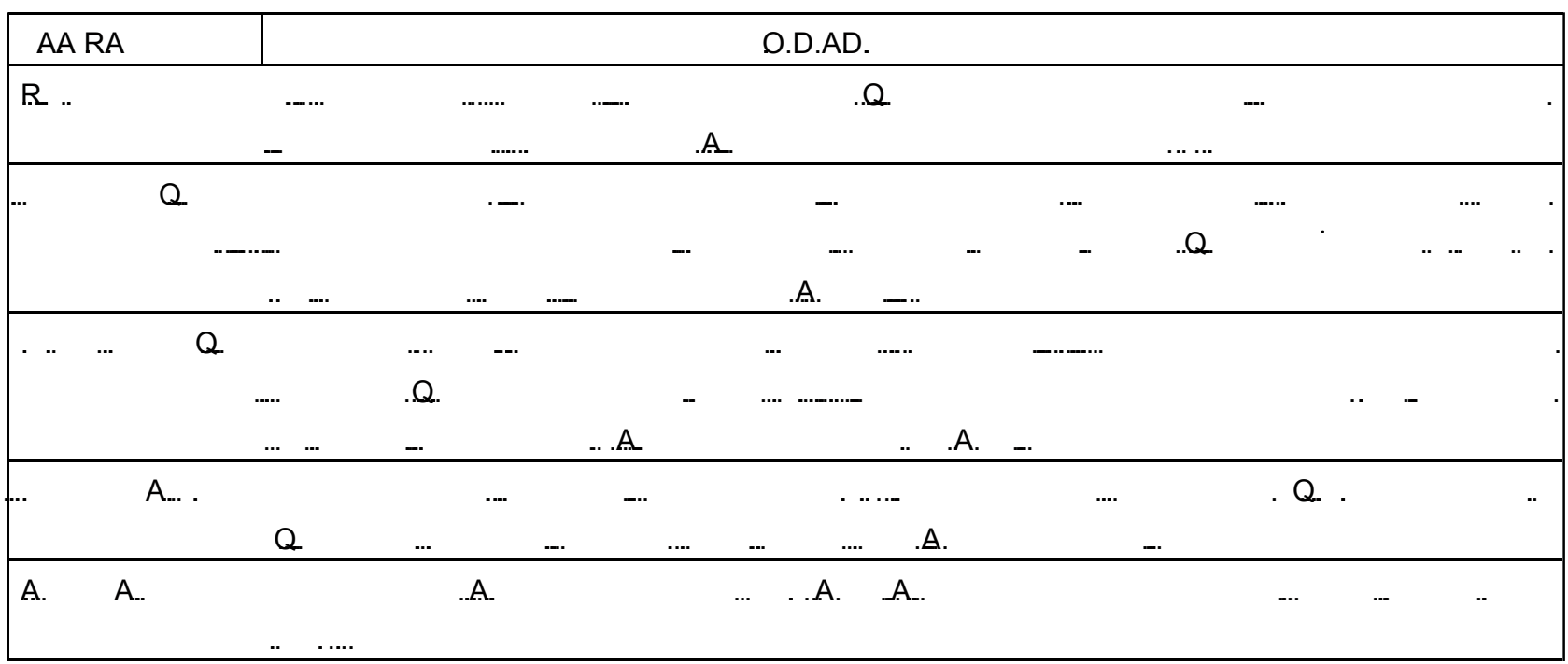


Ferriani et. al. (1998:4) escreveram sobre as conseqüências que os acidentes causam nas crianças. De acordo com os autores, os acidentes deixam:

"marcas psicológicas como os traumas, alteração da aceitação corporal. Pode ainda, afetar o desenvolvimento mental natural, a produtividade e aptidão nas atividades físicas, escolares. Deve ser lembrado também o comprometimento, de questões econômicas e sociais que o agravo em questão acarreta, tais como: custo da assistência à saúde e reabilitação, alteração do desempenho dos pais no trabalho. É preciso entender que os acidentes são um mal endêmico e requer um plano de ação permanente. A forma de atuação frente aos acidentes na infância entendemos que deva ser fundamentalmente preventiva" (Ferriani et. al. 1998, p.4).

Para Oga (1996), as medidas de intervenção para prevenção de acidentes infantis podem ser primárias e secundárias. As primárias ocorrem quando impedem a ocorrência do dano e as secundárias quando procuram tornar mínima a sua extensão, uma vez ocorrido.

S egundo o mesmo autor, em sua abordagem quanto aos tipos de intervenção, estas são classificadas em ativa e passiva.

"A intervenção ativa é aquela em que o próprio indivíduo busca formas e meios de alterar a situação vivenciada e requer uma ação consistente do indivíduo. J á a intervenção passiva parte do conhecimento de outras pessoas na transformação do fato ocorrido e solicita pouca ou nenhuma ação individual" (Oga,1996, p.46).

Schvartsman (2000), em palestra proferida em Maringá (PR), destacou que as medidas de intervenção ativas requerem ação do indivíduo e possuem baixa eficácia e as medidas de intervenção passivas não requerem ação direta do indivíduo e alcançam alta eficácia.

Este autor afirma que as atividades de educação/prevenção de intoxicações acidentais são atitudes isoladas, que nem sempre repercutem conforme o desejado; no entanto, enfatiza que, por não existir no nosso país uma política nacional de prevenção de acidentes, essas ações educativas em saúde podem ajudar a população, e às famílias em particular, a evitar que um novo acidente com substâncias tóxicas venha a ocorrer (Schvartsman, 2000)

Como uma das medidas ativas, este autor destaca o uso adequado dos medicamentos: os mesmos deveriam ser utilizados somente após consulta médica e prescrição médica. $\mathrm{Na}$ prática, observa-se que muitas famílias fazem uso de medicamentos sem orientação adequada, seguem orientação de vizinhos, parentes, balconistas e reportam-se às suas próprias experiências, vivenciadas em situação anterior (Aleixo, 2000).

U ma medida ativa que S chvartsman (2000) destaca, e a experiência em visitas domiciliares realizadas pelos profissionais do Centro de Controle de Intoxicações de Maringá confirmou, é o armazenamento adequado de agentes tóxicos. A orientação fornecida é que estes produtos devem ser armazenados em locais seguros, de preferência em armários trancados com chave. Este cuidado nem sempre é realizado, devido as condições de moradia das famílias ou ao esquecimento e descuido dos familiares.

As medidas de intervenção passivas não requerem participação direta do indivíduo e dependem de legislação específica.

Para um melhor entendimento, exemplifica-se uma forma de intervenção passiva de grande sucesso nos Estados Unidos. Em 1970, o governo criou as embalagens especiais de proteção à criança (EEPC) para produtos considerados tóxicos, visando dificultar a abertura das mesmas. Esta medida contribuiu para a diminuição da taxa de morbi-mortalidade por intoxicação nos últimos anos naquele país (Oga, 1996).

Entre as medidas passivas destaca-se, também, a diminuição da quantidade do produto por embalagem, pois sabe-se que a quantidade do princípio ativo é diretamente proporcional à gravidade da intoxicação (Oga, 1996).

Outra medida passiva para prevenir acidentes na infância está relacionado com a melhoria de informações fornecidas aos pais e às crianças, transmitidas através de órgãos governamentais, durante o período escolar, fazendo parte do currículo mínimo dos cursos. As crianças seriam motivadas para a prevenção e passariam a evitar que tais acidentes ocorram. Parte-se, também, do pressuposto que quando as crianças são sensibilizadas para evitar que algum acontecimento ocorra, no caso específico dos acidentes infantis, elas conseguem através 
do diálogo e/ou questionamento com seus pais ou outros adultos de seu convívio, sensibilizá-los para o comportamento preventivo.

De acordo com Quelhas (1998) entre as medidas passivas deve ser enfatizada a consciência prevencionista, que não é baseada em regras de segurança, mas na instrumentalização de crianças, pais e demais pessoas de seu convívio, como professores, de modo a conscientizá-los de seu direito à segurança, que deve ser garantido através da participação de toda a sociedade.

No entanto, para que ocorra uma efetiva cidadania prevencionista, é preciso que tanto as crianças como seus cuidadores tenham acesso a informações sobre os fatores de risco e perigo que estão interrelacionados no seu cotidiano e devem ser capacitados para a identificação dos fatores de risco.

\section{DISCUTINDO O COMPORTAMENTO PREVENTIVO NA FAMÍLIA}

Um dos desafios que o profissional de saúde enfrenta ao cuidar da família é a controvérsia sobre a existência ou não de uma saúde familiar como entidade distinta da saúde dos indivíduos. A saúde da família significa a soma da saúde dos indivíduos que a compõem ou, a família também é possuidora de um "estado de saúde" que pode ser identificado, diferente da saúde dos seus membros? (Elsen, 1994:65).

U ma referência mais direta ao papel importante que a família desempenha em relação à saúde de seus membros é feita por Turner (1970) apud Elsen (1994), ao chamar a atenção para o fato de que a família, por suas características especiais de proximidade e convivência, está melhor equipada e tem maiores condições para acompanhar o processo saúde e doença de seus membros.

Marcondes; Sossai (1977) apud Silva (1990), afirmam que existem dois tipos de fatores que condicionam os níveis de saúde dos indivíduos e famílias, um que abrange o nível sócio-econômico, as influências ecológicas e hereditariedade e outro que refere-se ao comportamento do indivíduo. Vários autores salientaram a importância e a influência, favorável ou não, do comportamento na determinação dos níveis de saúde dos indivíduos e famílias.

Hamburg; R ussel (1983), ao considerarem esta questão, foram bastante categóricos ao afirmarem que para uma melhoria da saúde do mundo, cumpre atribuir alta prioridade à relação entre saúde e comportamento, sendo que a sociedade em que vivemos pode facilitar ou dificultar uma mudança de comportamento que objetive a melhoria da saúde.

Seguindo esse raciocínio, concorda-se com Silva (1990) que ressalta:

"a preocupação com a identificação das variáveis que interferem positiva ou negativamente na determinação do indivíduo em engajar-se em ações que caracterizam um comportamento preventivo tem constituído problema de muitos estudos já realizados em vários campos da saúde, principalmente depois da divulgação do Modelo de Crenças em Saúde (MCS), idealizado por Hochbaum, Leventhal, Kegeles e Rosenstock durante a década de 50" (Silva, 1990, p. 4-7).

Pode-se conceituar comportamento preventivo como a situação em que:

"o indivíduo diante da percepção de sua vulnerabilidade a uma doença e da gravidade da mesma, identifica as possíveis ações e seus benefícios e posteriormente adota uma ação que seja adequada ou identifica e adota outras de eficácias semelhantes" (Rosenstock,1974 apud Silva, 1990, p.6).

De acordo com Rosenstock (1974) apud Silva (1990), o engajamento em uma ação percebida como benéfica depende da disposição para agir. A qual é determinada:

“...pelo grau de percepção ou crença do indivíduo na sua susceptividade, na gravidade da doença e nos benefícios da ação. Se a prontidão para agir é alta e as barreiras percebidas são mínimas é mais provável que a ação ocorra, mas se ela for baixa e as barreiras percebidas grandes, é provável, que ocorra uma inibição da ação. ... o resultado obtido no confrontamento das crenças com a percepção dos aspectos negativos que determinam o curso da ação é que este pode ser desencadeado ou influenciado por um evento estimulador que tanto pode ser interno (percepção do estado do corpo) como externo (interações interpessoais, impacto dos meios de comunicações, etc.)" (Rosenstock,1974 apud Silva, 1990, p.6). 
No âmbito familiar, destaca-se que cada família tem seu modo próprio de se organizar, estabelecido através da convivência e interação entre seus membros, seja ela do tipo nuclear, extensa ou alternativa. Existe em cada família um sistema de crenças, costumes e valores que é transmitido de geração a geração, e que deve ser respeitado.

Todavia, quando necessário, esse sistema de crenças deve ser discutido antes da proposição de alternativas de comportamento frente às condutas realizadas pelas famílias, pois geralmente diferem da forma preconizada pelos profissionais de saúde.

Aleixo (2000), durante entrevistas realizadas com familiares de crianças que se intoxicaram, constatou que o simples fato dos familiares terem permitido a realização do estudo, representou uma oportunidade para suscitar uma reflexão sobre suas atitudes (de forma consciente ou não).

Esta autora, também observou que a maioria das famílias se dispuseram a realizar mudança em seu comportamento após a experiência de intoxicação vivenciada por um de seus filhos; no entanto, o fato dos familiares refletirem sobre o assunto não faz com que ocorra mudança de comportamento:

"pois presenciamos nas diversas situações vivenciadas no dia- a-dia e também durante a realização destas entrevistas que nem sempre o fato de termos "boa vontade" e possuirmos determinação é suficiente para mudar alguma situação ou comportamento. É preciso buscar viabilizar condições adequadas e recursos disponíveis, sejam eles físicos, financeiros ou pessoais, além do apoio dos familiares e outras pessoas para que as mudanças esperadas se concretizem". (Aleixo, 2000, p.104).

Atribuímos estas considerações, ao sistema de crenças existentes em todas as famílias, pois na prática percebemos que as crenças influenciam de modo significativo as condutas e a forma como as famílias se organizam.

Concordamos com Nunes Sobrinho (1998), sobre a necessidade do desenvolvimento de habilidades na população infantil e em seus familiares para favorecer o reconhecimento dos riscos ambientais, e buscar maneiras de reduzi-los ou eliminá-los, e/ou tentar adaptar-se às situações do dia-a-dia que não podem ser modificadas de imediato e para as quais devam existir planejamento e utilização de estratégias de pequeno, médio e longo prazo.

\section{CONSIDERAÇÕES FINAIS}

Diante disso, destacamos a importância do estabelecimento de uma relação efetiva dos profissionais de saúde com os familiares durante a ocorrência de um acidente infantil, pois sem uma aproximação sincera, a interação com o outro não é completa. Existe a necessidade de criar um vínculo do serviço que atende a família desde o momento inicial da intervenção até a completa recuperação da criança.

Percebe-se a necessidade de refletirmos sobre este aspecto: a necessidade de mudança de comportamento dos profissionais que assistem as famílias. Esta atitude, se realizada, possibilitará uma melhor interação com os familiares, pois eles possuem condições de entenderem as orientações para a prevenção de acidentes desde que Ihes sejam transmitidas de forma gradativa e sequencial.

F inalmente, entende-se que enfocar a saúde na compreensão da vida quotidiana é propor-se a olhar o ser humano enquanto uma entidade biopsico-sócio-cultural percebendo sua complexidade e também a impossibilidade de sua apreensão, enquanto totalidade (Rezende, 1995).

ABSTRACT: The familiar preventive behavior is a result of the family's interaction wict health professionals, the and wich it environment's person. A bibliographic survey about the subject Preventio of accidents in thr familiar environment was made, aiming to discuss preventive behavior actions to avoid infantile intoxications. The active and passive interventions are detached as accidents prevention actions. The passive prevention actions are more affective, since they don't depend on the individual's intervention, but on the whole society's.Nevertheless, the need of a change in the development of the professionals who work in the health area is reinforced, as well as a new posture of the public policts formulators, through the control of the new products entered into the national market. 
KEY WORDS: Accidents home; Accidents prevention; F amily

RESUMEN: EI comportamiento preventivo familiar es resultado de la interacción de la familia com profesionales de salud, com la publicidad y com la persona de su ambiente. Se realizó un levantamiento bibliográfico sobre el tema prevención de accidentes en el ambiente familiar, com el objetivo de discutir medidas facilitadoras de comportamiento preventivo de intoxicaciones infantiles. Se destacan las intervenciones activas y pasivas como medidas de prevención de accidentes, siendo que las medidas pasivas de prevención son más eficaces, porque no dependen de la intervención del indivíduo pero de toda sociedad. Sin embargo, se refuerza la necesidad de transformación en a formación de los profesionales que trabajan en la salud, bien como de una neva postura de los formuladores de las políticas públicas, a través del control de los nuevos lanzados en el mercado nacional.

PALABRAS CLAVE: Accidentes domesticos; Prevencion de accidentes; Familia

\section{REFERÊNCIAS}

1 ALEIXO, E. C. S. Experiências vivenciadas pelos familiares de crianças que se intoxicaram no município de Maringá (PR). Londrina, 2000. p.147. Dissertação (Mestrado) Saúde Coletiva, Universidade Estadual de Londrina.

2 BACK, H. et al. Acidentes na infância. In: A Enfermagem em pediatria e puericultura. Rio de J aneiro: Atheneu ,1989.

3 BRASIL. Constituição da República Federativa do Brasil. 18. ed. São Paulo: Saraiva, 1998.

4 DEL CIAMPO, L. A .; RICCO, G. R. Acidentes na infância. Pediatria, São Paulo, v.18, n.4, p. 193-197, 1996.

5 ELSEN, I. Saúde familiar: a trajetória de um grupo. In: BUB, L. I.R. (Coord.). Marcos para a prática de enfermagem com famílias. Florianópolis: Ed. UFSC, 1994.

6 FERRIANI, M.G.C. et al. Aprender a prevenir acidentes brincando: um novo caminho para a promoção à saúde. In: CONGRESSO INTERNACIONAL DE SEGURANÇA NA INFÂNCIA E ADOLESCÊNCIA, 1, 1998, Niterói. Anais. Niterói: UFF, 1998.

7 HAMBURG, D.A.; RUSSEL, A. Conduta e saúde. Saúde do Mundo, p.27-9, 1983.

8 NUNES SOBRINHO, F.P. Acidentes na infância e na adolescência: medidas preventivas. In: CONGRESSO INTERNACIONAL DE SEGURANÇA NA INFÂNCIA E ADOLESCÊNCIA, 1, 1998, Niterói. Anais. Niterói: UFF, 1998.

9 OGA, S. Fundamentos de toxicologia. São Paulo: Atheneu, 1996.

10 QUELHAS .O. L. Prevenção de acidentes com crianças e adolescentes : conceito de cidadania prevencionista. In: CONGRESSO INTERNACIONAL DE SEGURANÇA NA INFÂNCIA E ADOLESCÊNCIA, 1, 1998, Niterói. Anais. Niterói: UFF, 1998

11 QUELHAS .O. L. Prevenção de acidentes em escolas. A proposta de uma nova metodologia. In: CONGRESSO INTERNACIONAL DE SEGURANÇA NA INFÂNCIA E ADOLESCÊNCIA, 1, 1998, Niterói. Anais. Niterói: UFF, 1998.

12 REZENDE, A.L.M. Quotidiano e saúde. In: REZENDE, A.L.M.; RAMOS, F.R.S.; PATR ÍCIO, Z.M. O fio das moiras - 0 afrontamento do destino no quotidiano da saúde. Florianópolis: Ed. UFSC, 1995.

13 SANTOS, O. H. Crianças acidentadas. Campinas: Papirus, 1998.

14 SCHILING, A. L. D. et. al. Prevenção de acidentes na infância. Acta Médica, v.15, p. 641-656, 1994.

15 SCHVARTSMAN, C. Prevenção de intoxicações acidentais na infância. 2000 (mimeo).

16 SILVA, S. Comportamento preventivo em saúde: exploração do conceito. Rev. Gaúcha Enferm. Porto Alegre: v.11, n.2, jul. 1990. p. 29-34.

17 WHALEY, L.F.; WONG. D. Enfermagem pediátrica; elementos essenciais à intervenção efetiva. 2 ed. R io de J aneiro: Guanabara, 1989. 